\title{
A PESQUISA-AÇÃO PARTICIPANTE COMO ESTRATÉGIA METODOLÓGICA PARA O ESTUDO DO EMPREENDEDORISMO SOCIAL EM ADMINISTRAÇÃO DE EMPRESAS
}

PARTICIPATORY ACTION RESEARCH AS A METHODOLOGICAL STRATEGY FOR THE STUDY OF SOCIAL ENTREPRENEURSHIP IN BUSINESS ADMINISTRATION

\author{
MARCOS BIDART CARNEIRO DE NOVAES \\ Mestre em Administração pela Universidade de São Caetano do Sul (USCS). \\ Professor do Departamento de Administração da Escola de Negócios Trevisan. \\ Rua Haddock Lobo, 867, ap. 235, Cerqueira César - São Paulo - SP - CEP $01414-001$ \\ E-mail: bidart@uol.com.br
}

ANTONIO CARLOS GIL

Doutor em Saúde Pública pela Universidade de São Paulo (USP). Professor do Departamento de Pós-Graduação da Universidade de São Caetano do Sul (USCS). Rua José Maria Lisboa, 1377, ap. 32, Cerqueira César - São Paulo - SP - CEP $01423-001$

E-mail: acgil@uol.com.br

Submissão: 5 fev. 2008. Aceitação: 27 set. 2008. Sistema de avaliação: às cegas dupla (double blind review). UNIVERSIDADE PRESBITERIANA MACKENZIE. Walter Bataglia (Ed.), p. 134-160. 


\section{RESUMO}

O presente ensaio tem como objetivo analisar e discutir como a pesquisa-ação participante pode ganhar espaço como estratégia metodológica em administração. Esta análise enfoca em especial o campo do empreendedorismo, e mais especificamente o campo do empreendedorismo social, ressaltando as vantagens e limitações da aplicação dessa estratégia de pesquisa. Procede-se, inicialmente, à análise dos principais paradigmas de pesquisa em administração e define-se a pesquisa-ação participante como modalidade de pesquisa crítica, inserida no paradigma humanista radical. A seguir, passa-se à identificação das características da pesquisa participante e ao seu contraste com outras modalidades de pesquisa, em especial com a observação participante e a pesquisa-ação. Os conceitos da pesquisa-ação participante são apresentados e os autores prosseguem apresentando uma revisão dos mais recentes trabalhos em que essa foi usada para apoiar pesquisas na área do empreendedorismo social. Concluem com a proposta de que a avaliação desses trabalhos se dê por outros conceitos que não os da pesquisa tradicional.

\section{PALAVRAS-CHAVE}

Metodologia; Pesquisa participante; Pesquisa-ação; Pesquisa crítica; Empreendedorismo social.

\section{ABSTRACT}

This essay aims to analyze and discuss how participatory action research can be applied as a methodological strategy in business administration. This analysis focuses mainly on the field of entrepreneurship and, more specifically, social entrepreneurship, highlighting the advantages and limitations of this research strategy. Firstly, the main research paradigms in business administration are analyzed and participatory-action research is defined as a research modality set 
within the radical humanist paradigm. Then, the characteristics of participatory research are identified and it is contrasted with other research modalities, specially with participant observation and action research. Participatory action research is then presented and the authors proceed with the presentation of a review of recent researches which it was used. They finish the work proposing that avaliation of works with this kind of methodology must be different then those used for traditional research.

\section{KEYWORDS}

Methodology; Participatory research; Action-research; Critical research; Entrepreneurship.

\section{INTRODUÇ ̃̃O}

A ciência da administração constituiu-se num momento em que o positivismo adquiria significativo prestígio, fazendo que respostas às questões ontológicas, epistemológicas, metodológicas e éticas relativas à nova disciplina fossem sendo procuradas em obras que emprestavam fundamento àquela orientação. Graças a essas respostas, os pesquisadores no campo da administração durante muito tempo sentiram-se seguros em relação às questões que emergiam de seus trabalhos e o modelo positivista tornou-se rigorosamente hegemônico. A ponto de até hoje alguns dos mais conhecidos manuais de pesquisa em administração publicados nos Estados Unidos (COOPER; SCHINDLER, 2003; ZIKMUND, 2003) restringirem os possíveis delineamentos de pesquisa aos estudos experimentais, estudos observacionais e levantamentos de campo, que são valorizados pela perspectiva positivista.

Embora a hegemonia positivista ainda seja evidente, verifica-se, no entanto, uma ênfase cada vez maior no campo da administração em pesquisas no campo de cunho interpretativista, em que a ênfase está não na procura da objetividade, mas na maneira como os sujeitos de pesquisa interpretam a realidade que vivenciam. Isso pode ser constatado no Brasil mediante análise dos anais dos últimos encontros da Associação Nacional de Pós-Graduação em Administração. É crescente o número de relatos de pesquisa elaborados sob as bases da fenomenologia, da etnografia, do interacionismo simbólico e da grounded theory. Também é possível constatar a presença, ainda que não muito significativa, de relatos de 
pesquisa publicados em periódicos de administração desenvolvidos nos moldes da pesquisa-ação (PA) e da pesquisa participante (PP), bem como da pesquisa-ação participante (PAP). Há autores que consideram essas como alternativas viáveis nos estudos realizados com o propósito de promover mudanças organizacionais e sociais (McMURRAY; PACE, 2004; McNIFF, 2000; THIOLLENT, I997; REASON; BRADBURY, 2008).

A PA e a PP são modalidades de pesquisa largamente utilizadas no âmbito de ciências sociais aplicadas como educação, serviço social e saúde pública, mas ainda são pouco frequentes no campo da administração. Talvez porque a perspectiva positivista - ainda predominante na administração - hesite em aceitar pesquisas em que o autor esteja comprometido com propostas transformadoras na realidade. Em pesquisas desenvolvidas no âmbito de outras ciências, como as já mencionadas, aceita-se que os pesquisadores se empenhem assumidamente na realização de pesquisas que visem não apenas conhecer a realidade vivenciada por essas pessoas, mas também modificá-la. Especialmente quando deparam com situações em que os integrantes dos grupos em estudo são muito carentes.

As alegações contra a interferência do pesquisador e dos sujeitos da pesquisa na realidade pesquisada vêm perdendo progressivamente sua força. Sobretudo porque na administração há campos em que a participação dos sujeitos da pesquisa, tanto na sua elaboração quanto na condução, análise e interpretação dos resultados, é altamente recomendável. Um desses campos é o do empreendedorismo social, em especial quando se trata de estudos envolvendo comunidades carentes, minorias socialmente fragilizadas ou portadores de necessidades especiais. Com efeito, os trabalhos de pesquisa desenvolvidos nesses campos visam à promoção e melhoria de condições da população que é objeto da pesquisa. Assim, as pesquisas que envolvem a participação dos sujeitos são recomendadas nesse campo, já que durante o seu processo se desenvolvem o aprendizado conjunto, a interdisciplinaridade e a interação multicultural (BARAZANGI, 2006; DEHLER; EDMONDS, 2006; REASON; BRADBURY, 2008).

O presente ensaio tem, pois, como propósito analisar e discutir a aplicabilidade da pesquisa-ação participante em administração, notadamente no campo do empreendedorismo social. Procede-se, para tanto, à análise dos principais paradigmas de pesquisa em administração com vistas a identificar suas matrizes teóricas. Passa-se então à caracterização de suas principais vertentes para, enfim, analisar suas aplicabilidade, vantagens e limitações como delineamento de pesquisa. 


\section{PARADIGMAS DA PESQUISA EM ADMINISTRAÇÃO}

A Administração como disciplina científica tem sido pródiga na elaboração de teorias, que têm sido úteis para garantir um sistema conceitual para as pesquisas, para fazer previsões e para orientar os procedimentos metodológicos a serem seguidos. Como, porém, a administração é uma ciência aplicada, a principal preocupação desses teóricos na construção de seus modelos e quadros de referência tem sido guiada por notável grau de pragmatismo. Isso tem favorecido a construção de teorias de alcance médio, em detrimento de teorias mais gerais, capazes de esclarecer acerca dos fundamentos ontológicos, epistemológicos e metodológicos da disciplina.

Um dos modelos adotados para descrever os paradigmas (ou visões de mundo) da administração é o apresentado por Burrel e Morgan (I979), que considera os pressupostos acerca da natureza das ciências sociais e da sociedade. Esse modelo indica quatro paradigmas, constituídos pela combinação das categorias referentes ao conhecimento proporcionado pela ciência social, que pode ser entendido como objetivo ou subjetivo, e as categorias referentes à natureza da sociedade, que pode ser concebida em termos de ordem e conflito (regulação e mudança radical). Uma das vantagens da utilização desse modelo é a consideração da posição do pesquisador, fator que influencia significativamente a pesquisa participante, que constitui objeto do presente ensaio da pesquisa participante.

Com base na combinação desses pressupostos, definem-se quatro paradigmas: I. funcionalista, que supõe a posição objetiva da ciência social e a de ordem da sociedade (regulação); 2. interpretativista, que supõe a posição subjetiva da ciência social e de ordem da sociedade (regulação); 3. estruturalista, que supõe a posição objetiva da ciência social e a de conflito da sociedade (mudança radical); e 4. humanista radical, que supõe a posição subjetiva de ciência social e de conflito da sociedade (mudança radical).

\subsection{O PARADIGMA FUNCIONALISTA}

O paradigma funcionalista é o dominante nas pesquisas em ciências sociais. Estreitamente vinculado ao positivismo, sua abordagem é objetiva, caracterizando-se pela preocupação para explicar a ordem social, o consenso, a integração social e a satisfação de necessidades. Adota o princípio de que toda instituição social é funcional ou exerce uma função, sendo, portanto, necessária. As pesquisas desenvolvidas segundo essa orientação buscam identificar relações manifestas e latentes dos fenômenos sociais. Assim, numa pesquisa sobre empreen- 
dedorismo, o pesquisador procura entendê-lo como atividade necessária para a estabilidade da sociedade. Numa época caracterizada pela diminuição dos postos de trabalho formais e ameaçada pelo fim do emprego (BRIDGES, I995), o empreendedorismo desempenharia, então, uma função social, a de constituir alternativa para ocupação e geração de renda.

Há um estreito relacionamento entre conceitos funcionalistas e a teoria geral dos sistemas. O funcionalismo enfatiza os sistemas de relacionamento e a unificação das partes e dos subsistemas em um todo funcional. Assim, contribui para o entendimento dos fatos sociais em termos de estruturas, processos e funções e para a compreensão das relações existentes entre esses componentes.

O pensamento sistêmico funcionalista foi elaborado por Parson (I95I). Segundo esse autor, há três níveis administrativos na estrutura hierárquica das organizações complexas: o nível técnico (produtor), o nível organizacional (direção), e o nível institucional ou comunitário. O sistema de administração no nível técnico diz respeito, especialmente, à racionalidade técnico-econômica, e procura criar a certeza "fechando" o núcleo técnico a numerosas variáveis. É essa busca de certeza e circunscrição que inibe em muitos casos pesquisadores funcionalistas de aceitarem a visão aberta e flexível de outras formas de pesquisa. O sistema de administração no nível institucional enfrenta o mais alto grau de incerteza em termos das alimentações provenientes do ambiente, sobre as quais ela exerce pouca ou nenhuma influência.

Em I950, Ludwig van Bertalanffy (I973) publicou "The theory of open systems in physics and biology" na revista Science, e em 1956, o livro General system theory. Foram publicações que influenciaram autores em diversas linhas de estudo, incluindo a teoria das organizações baseada no funcionalismo. O próprio Bertalanffy (I973) alertava quanto aos perigos da visão restrita a função e estruturas, já falando de complexidade. Entende-se por complexidade um grande número de problemas e variáveis presentes em uma situação, que é a condição normal que as organizações e os administradores devem enfrentar.

\subsection{PARADIGMA INTERPRETATIVISTA}

O paradigma interpretativista, assim como o funcionalista, adota a abordagem social da regulação, mas sua concepção de análise da sociedade é subjetivista. O paradigma interpretativista parte do princípio de que a realidade social não existe em termos concretos, e sim como um produto das experiências intersubjetivas das pessoas. As pessoas é que constroem e mantêm simbolicamente a realidade. Assim, a explicação dos fenômenos sociais é procurada na consciência social e na subjetividade, no quadro de referência do participante e não do observador. 
Nesse paradigma o mundo social é entendido como um processo criado pelos indivíduos. Mas, assim como no funcionalismo, pressupõe que o mundo é coeso, integrado e ordenado pela ação das pessoas. Por essa razão, a dominação, a contradição, o conflito e a potencialidade de mudança não são considerados relevantes na explicação do comportamento social. Nesse contexto, o empreendedorismo é estudado então com base na representação das pessoas. Sua unidade simbólica é constituída pela realidade simbólica compartilhada pelos sujeitos. Logo, os estudos sobre empreendedorismo tenderão a enfatizar o consenso e a solidariedade.

Uma das múltiplas vertentes da teoria geral dos sistemas sistêmica está intimamente ligada às visões interpretativistas. É a que traz em seu bojo o conceito de complexidade, aqui compreendida como grandes quantidades de interações que desafiam capacidades de calcular, bem como incertezas, indeterminações e fenômenos aleatórios (MORIN, 2006). Essa vertente possui a perspectiva de fornecer para a ciência da administração, carente de uma ontologia própria, um salto paradigmático.

\subsection{O PARADIGMA ESTRUTURALISTA RADICAL}

O paradigma estruturalista radical fundamenta-se na perspectiva marxista. Assim como o paradigma funcionalista concebe o mundo social como determinado por estruturas concretas e reais, mas procura explicar os fenômenos a partir dos modos de dominação, das contradições e do conflito estrutural. Seus adeptos, por sua vez, advogam a mudança radical da sociedade do ponto de vista objetivo.

Para os estruturalistas radicais a sociedade contemporânea é caracterizada por conflitos entre as classes, que geram crises políticas e econômicas e acabam por promover mudanças radicais na sociedade. É pelo conflito que os seres humanos se emancipam das estruturas sociais em que vivem. Assim, os estudos desenvolvidos sob a perspectiva do estruturalismo radical centram-se na identificação dos conflitos inerentes aos processos empreendedores e na maneira como os vários modos de dominação os influenciam. Essa perspectiva enfatiza também a busca dos meios que possibilitem transcender essa dominação.

\subsection{O PARADIGMA HUMANISTA RADICAL}

O paradigma humanista radical está estruturado na combinação da visão subjetivista com a teoria da mudança radical. A ordem social é entendida como produto da coerção e não do consentimento. Assim, os adeptos desse paradigma comprometem-se com uma visão de sociedade que enfatiza a importância de transcender os limites dos arranjos sociais existentes. 
Os estudos sobre empreendedorismo desenvolvidos segundo essa perspectiva tendem, pois, a enfatizar a identificação dos conflitos inerentes aos processos empreendedores por parte de grupos oprimidos e à maneira como os vários modos de dominação os influenciam. O empreendedorismo social é visto por autores filiados a essa tendência, como uma das manifestações daquela "outra globalização" constituída por redes e alianças entre movimentos, lutas e organizações locais ou nacionais que se mobilizam para lutar contra a exclusão social, a degradação das condições de trabalho, o desemprego, o declínio das políticas públicas, a destruição do meio ambiente e da diversidade e os ódios interétnicos produzidos diretamente ou indiretamente pela globalização liberal (SANTOS, 2002; MELO NETO; FROES, 2004).

Na visão "bancária" da educação, e consequentemente do ensino da administração e do empreendedorismo, o saber é uma doação dos que se julgam sábios aos que julgam nada saber (FREIRE, 2005, p. 67). Com essa visão, a tendência será sempre a de manipular grupos para se adequar ao conhecimento administrativo e organizacional do paradigma vigente.

Para Silva e Silva (2006, p. I25), "uma proposta de construção de conhecimento comprometida com a mudança social implica tomar criticamente a realidade como objeto de pesquisa e requer a inserção do pesquisador na realidade social". Essa inserção, por sua vez, exige explicitação da intencionalidade, sem nenhum pressuposto de neutralidade. Explicitação não só da ideologia do pesquisador, mas de sua postura em relação ao ensino da administração e do empreendedorismo. Na medida em que a pesquisa-ação participante, em especial quando realizada com adultos em comunidades carentes, é uma prática educativa, desde as suas origens, os dilemas do pesquisador surgem por vezes de sua postura ideológica, que precisa ser explicitada.

A abordagem crítica que caracteriza a PAP, além de se preocupar com a apresentação de uma visão ampla e dinâmica da realidade, procura conscientemente compreender os fatos inseridos em suas influências econômicas, políticas e culturais, privilegiando um enfoque qualitativo (GIL, 2003). Essa perspectiva envolve abandonar o "mundo seguro do funcionalismo, no qual as pesquisas geram hipóteses e modelos teóricos do trabalho empírico, para abraçar a incerteza e a produção de um conhecimento que o próprio pesquisador pode questionar em um ou outro momento" (PAULA, 2008, p. XI). Uma das características da pesquisa crítica é, pois, essa reflexividade do pesquisador sobre seu trabalho e sobre si próprio como elemento que participa desse trabalho.

Para Monteiro (2007), a pesquisa-ação é uma pesquisa experimental par excellence, uma vez que as experiências são vivenciadas pelo investigador em termos de intervenção, participação e colaboração. As pesquisas participativas 
culminam com a interpretação de uma experiência transformadora vivenciada entre pesquisador e comunidade investigada. A idéia desse autor é de que a reflexividade é um processo que se materializa em texto. O conhecimento produzido deve ser efetivado em registros que expressem a construção elaborada durante determinado processo de formação e transformação.

É, portanto, no âmbito deste último paradigma que os autores deste trabalho situam a pesquisa-ação participante, cujas similaridades e diferenças com outras formas de pesquisa, origens e fundamentos são apresentadas nas seções que se seguem.

\section{PESQUISA PARTICIPANTE E OUTRAS MODALIDADES DE PESQUISA}

A pesquisa participante apresenta interfaces com outras modalidades de pesquisa. Assim contrasta-se, a seguir, a pesquisa participante com outros tipos de pesquisa com as quais apresenta similaridade.

\subsection{OBSERVAÇÃO PARTICIPANTE (OP)}

A observação participante constitui a rigor um método de pesquisa em que o pesquisador procura tornar-se um membro do grupo observado, e dessa forma compartilhar as experiências de vida para melhor compreender seus hábitos e convenções sociais. Sua origem pode ser encontrada nos trabalhos do antropólogo Bronislaw Malinowski (I884-I942), que viveu entre os nativos das ilhas Trobriand, na Nova Guiné, de I9I5 a I9I8. Essa técnica foi amplamente utilizada pelos sociólogos da Escola de Chicago nas décadas de I920 e I930 no estudo de problemas urbanos.

Um importante trabalho desenvolvido nessa escola com a utilização da pesquisa participante foi Sociedade de esquina, de W. F. Whyte (2005), que contribuiu significativamente para a orientação de pesquisadores interessados no método. Desse livro depreendem-se "dez mandamentos da observação participante": I. trata-se de um processo longo; 2 . o pesquisador precisa estar preparado para lidar com situações inesperadas; 3. exige interação entre o pesquisador e o pesquisado; 4. exige que o pesquisador se diferencie do grupo e abandone esforços de imersão total; 5 . exige um mediador entre o pesquisador e a comunidade sobre ou com a qual se pesquisa; 6 . exige do pesquisador a consciência de que ele mesmo está sendo o tempo todo observado e avaliado e que "seus passos durante o trabalho de campo são conhecidos e muitas vezes controlados por membros da população 
local"; 7. implica saber ouvir, escutar e fazer uso de todos os sentidos, deixando com o tempo que os dados venham sem esforço ao pesquisador; 8. exige rotinas de trabalho, autodisciplina e anotações sistemáticas; 9. aprendizado com erros; e ıo. saber lidar com cobranças sobre qual utilidade advirá da pesquisa para o grupo (VALADARES, 2007, p. I54).

Godoy (2006, p. I26) propõe que a observação participante seja compreendida em uma acepção mais restrita como uma das "técnicas etnográficas” (aspas da autora) utilizadas para colher dados de campo, da mesma forma que entrevistas, histórias de vida e diários. Já para Yin (200I), a observação participante pode ocorrer enquanto o pesquisador assume funções dentro do grupo e participa dos eventos estudados. Também a classifica, no entanto, como técnica de pesquisa que faz parte do esforço para coleta de evidências e não para transformação da realidade, como é o caso da proposta metodológica da pesquisa participante.

A utilização da técnica da OP não implica, como ocorre na PP, compromisso com a comunidade em que se desenvolve a pesquisa, nem superação da oposição sujeito/objeto. O que significa que sua utilização é pacífica nas pesquisas desenvolvidas sob as perspectivas funcionalistas e interpretativistas.

\subsection{PESQUISA-AÇÃO}

A PA é definida por Thiollent (1985, p. I4) como uma pesquisa com base empírica, "realizada em estreita associação com uma ação ou com a resolução de um problema coletivo e no qual os participantes representativos da situação ou do problema estão envolvidos de modo cooperativo ou participativo". O termo PA foi cunhado em I946 por Kurt Lewin (I946), ao desenvolver trabalhos que tinham como propósito a integração de minorias étnicas à sociedade norte-americana. Assim, definiu PA como a pesquisa que contribui não apenas para a produção de livros, mas que conduz à ação social.

A PA tem características situacionais, já que procura diagnosticar um problema específico numa situação específica, com vistas a alcançar algum resultado prático. Diferentemente da pesquisa tradicional, não visa obter enunciados científicos generalizáveis. Embora a obtenção de resultados semelhantes em estudos diferentes possa contribuir para algum tipo de generalização. Martins (2006, p. 47-48) a vê, no âmbito das organizações, como "uma proposta de pesquisa mais aberta, com características de diagnóstico e consultoria para clarear uma situação complexa e encaminhar possíveis ações, especialmente em situações insatisfatórias ou de crise".

Macke (2006) apresenta um quadro bem completo da pesquisa-ação, identificando as bases filosóficas para uma filosofia do conhecimento e da ação, e con- 
sequentemente da ciência da ação, em que o conhecimento estaria a serviço dessa ação e de processos de mudança, desvinculado do conhecer por conhecer. A mesma autora traça o quadro da discussão entre aqueles que veem a PA como uma forma ou variante do estudo de caso e outros autores que a enxergam como uma modalidade que vai além do estudo de caso. Isso porque, segundo Argyris (apud MACKE, 2006, p. 223) na pesquisa-ação o "envolvimento dos participantes no processo de mudança faz com que eles pensem e reflitam sobre o que estão fazendo".

O notável desenvolvimento de pesquisas apresentadas sob essa rubrica possibilita hoje identificar diferentes modalidades de pesquisa-ação. Assim, Tripp (2005) apresenta cinco modalidades de PA: I. PA técnica, em que o pesquisador age de modo inteiramente mecânico, lendo o manual; 2. PA prática, na qual o pesquisador projeta as mudanças; 3. PA política, em que o pesquisador sente a necessidade de engajar-se na política para mudar o "sistema"; 4. PA socialmente crítica: modalidade de pesquisa-ação política em que se trabalha para mudar ou contornar o modo de agir dominante do sistema; e 5. PA emancipatória, também uma variação da pesquisa-ação política, que tem como meta mudar o statu quo não apenas para si mesmo e para os companheiros mais próximos, mas numa escala mais ampla do grupo social como um todo.

Franco (2005) considera que o caráter emancipatório da PA se dá quando a transformação é percebida como necessária pelo próprio grupo, por meio de um processo de reflexão crítica coletiva, do qual o pesquisador participa. Chama a essa modalidade de PA crítica, contrapondo-a a outras experiências, como aquela em que a função do pesquisador é a de conferir um enfoque científico a um processo de mudança desencadeado pelos sujeitos, e que é denominada PA colaborativa. $\mathrm{Ou}$, ainda, a trabalhos em que a transformação é previamente planejada, sem a participação dos sujeitos, tendo o pesquisador a tarefa de acompanhar os efeitos e avaliar os resultados, modalidade essa que a autora denomina PA estratégica. A condição para que a pesquisa-ação possa ser considerada crítica "é o mergulho na práxis do grupo social em estudo, do qual se extraem as perspectivas latentes, o oculto, o não familiar que sustentam as práticas, sendo as mudanças negociadas e geridas no coletivo" (FRANCO, 2005, p. 486).

O surgimento dessas tendências críticas e emancipatórias com a denominação de PA de certa forma dissolveu as diferenças iniciais que havia em relação à PP.

\subsection{PESQUISA PARTICIPANTE}

Existem semelhanças entre a PP e a PA, pois ambas caracterizam-se pela interação entre os pesquisadores e as pessoas envolvidas nas situações investigadas. Mas há uma grande diferença, que está no caráter emancipatório da PP. Enquanto 
a PA supõe alguma forma de ação, que pode ser de caráter social, educativo, técnico ou outro, a PP tem como propósito fundamental a emancipação das pessoas ou das comunidades que a realizam. Ou seja, a PA pode, dependendo de quem a pratica, ter um caráter emancipatório. Já a pesquisa participante só é escolhida por quem de antemão se propõe a lutar junto a comunidades excluídas.

Essas diferenças têm relação direta com a origem das duas modalidades de pesquisa. Enquanto a PA iniciou-se nos Estados Unidos no período que se seguiu à Segunda Guerra (LEWIN, I946), a PP surgiu na América Latina como meio para alcançar a articulação de grupos marginalizados (BRANDÃO; STECK, I999; GAJARDO, I999; SILVA E SILVA, I99I). Seus criadores foram pessoas que participavam de programas educacionais voltados para trabalhadores rurais (GIANOTTEN; WITT, I999) e sua estratégia consistia em fomentar o processo de formação de consciência crítica das comunidades para sua inserção em processos políticos de mudança.

Pode-se definir pesquisa participante (PP) como uma modalidade de pesquisa que tem como propósito "auxiliar a população envolvida a identificar por si mesma os seus problemas, a realizar a análise crítica destes e a buscar as soluções adequadas" (LE BOTERF, I984, p. 52). Trata-se, portanto, de um modelo de pesquisa que difere dos tradicionais porque a população não é considerada passiva e seu planejamento e condução não ficam a cargo de pesquisadores profissionais. A seleção dos problemas a serem estudados não emerge da simples decisão dos pesquisadores, mas da própria população envolvida, que os discute com os especialistas apropriados.

A PP deve ser compreendida, segundo a formulação de Brandão e Steck (2006, p. I2), como um "repertório múltiplo e diferenciado de experiências de criação coletiva de conhecimentos destinados a superar a oposição sujeito/objeto no interior de processos que geram saberes e na sequência de ações que aspiram gerar transformações”. Há, portanto, vários modelos de PP, já que por sua própria natureza ela é flexível, e como tal adapta-se a diferentes situações concretas, conforme os objetivos perseguidos, os recursos disponíveis e o contexto sociopolítico em que se desenvolve. É importante, no entanto, distinguir a PP de pesquisas que se valem apenas da observação participante.

As origens da PP estão na ação educativa. Sua principal influência encontrase nos trabalhos de Paulo Freire (2005) relativos à educação popular. Seu método de alfabetização a partir da leitura do alfabetizando de seu próprio contexto sóciohistórico é que proporcionou as bases da pesquisa participante. Assim, graças aos trabalhos de educadores como João Bosco Pinto (i976), Marcela Gajardo (I98I) e Carlos Rodrigues Brandão (I98I) desenvolveu-se a chamada vertente educativa da PP. "Uma pesquisa que é também uma pedagogia que entrelaça 
atores-autores e que é um aprendizado no qual, mesmo quando haja diferenças essenciais de saberes, todos aprendem uns com os outros e através dos outros", conceitua Brandão e Steck (2006, p. I3).

Além da linha voltada para a educação, a PP também tem uma vertente sociológica. Essa foi inaugurada na América Latina pelo colombiano Orlando Fals Borda (I972), que postulou o método do "estudo-ação" como práxis perante os problemas derivados da dependência da ação imperialista e da exploração oligárquica. Fals Borda propõe uma postura de devolução do conhecimento aos grupos que deram origem a esse conhecimento. Isso exige que o pesquisador se envolva como agente no processo que estuda, já que tomou uma decisão em favor de determinadas alternativas, aprendendo assim não apenas por meio da observação, mas do próprio trabalho com as pessoas com quem se identifica (FALS BORDA, I980).

Os seis princípios metodológicos a serem seguidos para a investigação-ação conforme Fals Borda (1982) são: I. Autenticidade e compromisso, pelo qual intelectuais, técnicos e cientistas devem demonstrar honestamente seu compromisso com a transformação social proposta, sem precisarem fazer passar pelo que não são; 2. Antidogmatismo, pelo qual é garantido ao grupo com o qual, para o qual e sobre o qual se estuda que esse tem liberdade política, religiosa e organizacional em geral; 3. Restituição sistemática, que garante ao grupo que o conhecimento adquirido lhe será devolvido em linguagem que respeite suas tradições culturais, de forma sistemática e organizada; 4. Feedback aos intelectuais orgânicos, pelo qual se garante que os trabalhos gerem contribuição expressa com clareza na exposição teórica e observações sobre sua aplicabilidade em situações similares, de forma dialética, das bases para os intelectuais engajados; 5 . Ritmo e equilíbrio de ação e reflexão, que garante a articulação do conhecimento concreto com o geral, do conhecimento local com o nacional e o global, da formação social com o modo de produção; 6 . Ciência modesta e técnicas dialogais, baseadas em duas idéias: a primeira, a de que a ciência deve ser realizada mesmo em situações insatisfatórias e primitivas, sem que isso signifique falta de ambição; a segunda, a de que o pesquisador deve aprender a ouvir discursos em diferentes sintaxes, romper com a assimetria das relações sociais e incorporar pessoas por mais humildes que sejam como seres ativos e pensantes nos esforços de pesquisa.

Vale ressaltar que princípios como o segundo e o terceiro mencionados não são privilégios dessa forma de pesquisa, mas o pesquisador colombiano fez questão de os registrar para evitar ações puramente militantes ou sem contato com a academia.

Qualquer que seja a vertente, no entanto, o caráter emancipatório da PP constitui sua principal característica. Seu principal ponto fraco, por sua vez, 
sempre foi apontado como o uso militante por pesquisadores mal preparados (DEMO, I984).

\subsection{PESQUISA-AÇÃO PARTICIPANTE}

As divergências entre pesquisadores associados à pesquisa-ação e à pesquisa participante conduziram a uma espécie de compromisso em torno da pesquisaação participante (PAP) como uma tentativa de minimizar as diferenças e enfatizar as semelhanças entre as duas modalidades de pesquisa participativa. Embora haja autores como Macke (2006), que propõem designar todas as modalidades de pesquisa participativa como pesquisa-ação como PA, os autores deste trabalho consideram necessário manter a terminologia pesquisa-ação participante, para enfatizar a característica educativa da PAP e suas origens latino-americanas, vinculadas a trabalhos como os de Fals Borda (200I, I982, I980, I977) e Paulo Freire (2005, I98I, I977).

A proposta da pesquisa-ação participativa ou pesquisa-ação participante (PAP) ganhou força graças à participação de Fals Borda no Simpósio Mundial de Cartagena, realizado em I977, que definiu a investigacion-acción participativa como uma metodologia inserida num processo vivencial para os grupos de base, que inclui simultaneamente educação de adultos, pesquisa científica e ação política (FALS BORDA, I977).

Embora vinculada originariamente a movimentos políticos e sociais latinoamericanas, a PAP difundiu-se e vem ganhando adeptos em outras partes do mundo. Na década de I990, passou a ser utilizada em países de língua inglesa a expressão Participatory Action-Research. Em I99I, o sociólogo William Foote Whyte, um dos pioneiros na utilização do método da observação participante nos Estados Unidos, organizou um livro com esse título. Whyte (I99I), no entanto, não vincula seu trabalho à PAP, tal como foi concebida na América Latina e apresenta como principais influências a análise sociotécnica norte-americana e a work democracy research, de origem escandinava (THORSRUD, I977; ELDEN, I979).

Já McTaggart, em I997, organizou um livro com o mesmo título, abordando o desenvolvimento da PAP em diferentes países. McTaggart (I997) afirma que a adição do termo participante é necessária para distinguir a autêntica PAP dos vários tipos de pesquisa que se abrigam sob esse título. Embora apresente contribuições de autores com diferentes perspectivas, McTaggart (I997) enfatiza a influência de Paulo Freire na PAP, e Orlando Fals Borda assina um dos capítulos da obra.

Muitas obras tratando de PAP têm sido publicadas em língua inglesa, algumas tratando de áreas específicas como Saúde (KOCH; KRALIK, 2006), Educa- 
ção (McINTYRE, 2007; JAMES et al., 2007) e Geografia (KINDON et al., 2007). A maioria faz menção às origens latino-americanas. O Handbook of Action Research: Participative Inquiry and Practice, (REASON; BRADBURY, 2008) uma das mais prestigiadas obras que tratam de pesquisa qualitativa, inclui em sua edição original de 200 I um capítulo de autoria de Fals Borda sobre PAP.

A PAP vem encontrando adeptos em muitos países da África (MEYER, 2006) e da Ásia. Na Índia, em I982, foi fundada a Society for Participatory Research in Asia, uma organização voluntária que fornece suporte a iniciativas populares. Outro país asiático em que a PAP vem se firmando é Bangladesh, onde foi realizado, em 2004, The International Workshop on Participatory Action Research. A PAP vem sendo usada também como ferramenta para melhor compreender e atuar em regiões devastadas por conflitos, como a antiga Iugoslávia, Haiti, Moçambique e outros países (JOHANNSEN, 200I).

Não há como identificar grandes diferenças entre PAP e PP, notadamente em sua vertente sociológica, desenvolvida na América Latina. A PAP, tal como vem sendo praticada em países de língua inglesa, no entanto, pode ser considerada como o produto da influência da PP sobre a PA.

A PAP deve ser compreendida como uma das modalidades de pesquisa comprometidas com o modelo de "aplicação edificante" do conhecimento científico (SANTOS, I989, p. I59), que tem, entre outros, os princípios: I. tem lugar em situações concretas em que quem aplica está ética, existencial e socialmente comprometido; 2. é um processo argumentativo entre grupos que lutam pela decisão do conflito a seu favor; 3 . envolve o cientista na luta pelo equilíbrio do poder, obrigando-o assim a tomar o partido daqueles que têm menos poder; 4. aceita que os limites e deficiências dos saberes locais não justificam a recusa desses, porque isso significa desarmar argumentativa e socialmente seres competentes.

\section{PESQUISA-AÇÃO PARTICIPANTE E O EMPREENDEDORISMO SOCIAL}

Considera-se, a seguir, a evolução do conceito do empreendedorismo social, cuja emergência está a exigir a utilização da PAP como forma privilegiada de investigação. Com efeito, a PAP é hoje muito usada para aproximar pesquisadores e grupos de sujeitos da prática. Constitui um suporte epistemológico e metodológico que apoia de forma efetiva uma "tradução" necessária para que grupos oriundos de diferentes meios e com diferentes necessidades se aproximem. Utiliza-se a aqui o termo tradução para designar o processo por meio do qual "uma necessidade, uma aspiração, uma prática numa dada cultura pode 
ser tornada compreensível e inteligível para outra cultura" (SANTOS, 2007, p. 3I). Considera-se também nesta seção como a PAP vem sendo usada para apoiar a aproximação com grupos de empreendedores, de forma especial nos estudos sobre empreendedorismo social.

\subsection{CONCEPÇÕES DE EMPREENDEDORISMO}

O empreendedor é apresentado em estudos orientados pela ideologia neoliberal como um inovador em busca de novas oportunidades, novos produtos, processos, formatos organizacionais, insumos, matérias-primas etc. Esse privilégio dado a ações individuais deve-se a uma perspectiva baseada em uma racionalidade estritamente econômica e focada em atributos pessoais do empreendedor, como autoconhecimento, controle, baixa aversão ao risco e capacidade de romper com padrões. Como esses atributos estão em princípio desigualmente distribuídos na população, apenas a alguns indivíduos estaria permitido empreender.

Cabe considerar, ainda, que o termo empreendedorismo está fortemente alinhado à ideologia neoliberal de redução do estado e ligado a fenômenos como a flexibilização do trabalho e terceirização. Também aparece diretamente associado à criação e desenvolvimento de novos e pequenos negócios e à identificação e formação de proprietários-gerentes ou empreendedores-proprietários (ALBAGLI; MACIEL, 2003).

Na última década do século XX, define-se, no entanto, uma nova modalidade de empreendedorismo, o social, que difere do empreendedorismo propriamente dito em dois aspectos: I. não produz bens e serviços para vender, mas para solucionar problemas sociais; e 2. não é direcionado para mercados, mas para segmentos populacionais em situação de risco social, como pobreza, miséria, risco de vida e exclusão social (MELO NETO; FROES, 2004). Segundo essa compreensão, empreendedorismo é também o conjunto de iniciativas implementadas por segmentos sociais excluídos, organizações, comunidades e instituições públicas em busca de novas possibilidades para grupos sociais menos favorecidos (ALBAGLI; MACIEL, 2003).

Alvord et al. (2004) sustentam que o empreendedorismo tradicional é medido e testado pela sua capacidade de criar organizações com fins lucrativos, viáveis e sustentáveis ao longo do tempo. Já o empreendedorismo social deve ser testado pela sua capacidade de provocar mudança social duradoura. É um processo que estimula o aumento da participação em ações empreendedoras locais, o aumento do sentimento de conexão das pessoas com sua cidade, terra e cultura, e o surgimento de novas idéias. Aliás, de alternativas sustentáveis para o desenvolvimento, inclusão social, maior autosuficiência e melhoria da qualidade de vida das 
pessoas e da comunidade. Dentre as áreas abrangidas pelo empreendedorismo social destacam-se: I. educação e inclusão digital; 2. moradia de baixo custo; 3. reciclagem e indústrias limpas; 4 . agricultura e floresta; 5 . uso da água e energias alternativas; 6. saúde e nutrição comunitárias; 7. educação e alfabetização; 8. diversidade e multiculturalismo; 9. oportunidades para deficientes; Io. serviços sociais em geral; II. apoio ao empreendedorismo e microcrédito; e I2. direitos humanos (DEMIRDJIAN, 2007).

Apesar da distinção entre o empreendedorismo em sua acepção clássica e o empreendedorismo social, o que se constata nos chamados países emergentes é que o apoio ao empreendedorismo vem assumindo cada vez mais as características de empreendedorismo social. Tanto é que muito do apoio conferido ao empreendedorismo no Brasil dá-se por conta de órgãos governamentais e de organizações da sociedade civil, que elaboram políticas explícitas de incentivo aos menos favorecidos, muitas dessas políticas voltadas para a abertura de pequenos negócios, muitas vezes incentivando até a abertura de negócios informais. Nesse sentido, uma análise de conteúdo dos documentos elaborados pelo Serviço Brasileiro de Apoio às Micro e Pequenas Empresas (Sebrae) ou por organismos de microcrédito como o Banco do Povo será suficiente para demonstrar as características sociais do empreendedorismo preconizado.

\section{A PESQUISA SOBRE EMPREENDEDORISMO SOCIAL}

Verifica-se o aumento nos últimos anos do interesse na investigação de outras manifestações do empreendedorismo, tais como: I. empreendedorismo indígena (PEREIRA, 2003; LINDSAY, 2005); 2. empreendedorismo em comunidades rurais (JENKINS, 2005); 3. em comunidades de pescadores (UFRJ, 2005); 4. de artesãos (OLSON, I999); 5. empreendedorismo entre portadores de necessidades especiais (VAN NIEKERK et al., 2006; LORENZO et al., 2007); 6. empreendedorismo cooperativista (THOMAS, 2004; MARTINEZ; PIRES, 2002); 7. empreendedorismo entre afro-descendentes (BOXILL, 2003); 8. empreendedorismo entre latino-americanos de segunda geração (FERNÁNDEZ-KELLY; KONCZAL, 2005); e 9. redes de empreendimentos sociais (GREVE; SALAFF, 2003), entre outros. Nesses estudos são abordados aspectos ligados à realidade social de cada grupo e à maneira como cada um deles lida com obstáculos específicos, preconceitos e também oportunidades.

Da análise desses relatos depreende-se que na investigação do empreendedorismo tradicional os pesquisadores se valem especialmente de levantamentos e de estudos de caso. Já na investigação de outras manifestações de empreendedorismo - sobretudo referentes a grupos mais carentes ou de certa forma 
excluídos - a preferência dos pesquisadores recai em delineamentos alternativos. As múltiplas manifestações de empreendedorismo indicam a necessidade de novas abordagens acerca do fenômeno empreendedor, que possibilitem o entendimento do processo empreendedor com base na experiência de vida e nas representações das pessoas. Assim, assume importância a realização de pesquisas de cunho qualitativo na investigação do fenômeno empreendedor. Tanto as pesquisas fenomenológicas e etnográficas quanto as que seguem o modelo da grounded theory podem contribuir para o conhecimento de múltiplos aspectos do empreendedorismo do ponto de vista dos próprios empreendedores. Daí as pesquisas sobre empreendedorismo que vêm sendo desenvolvidas sob o enfoque fenomenológico (COPE, 2005; SEYMOUR, 2006; SHAW; CARTER, 2007), etnográfico (BRUNI et al., 2005; FERNÁNDEZ-KELLY; KONCZAL, 2005) e da grounded theory (WEERAWARDENA; MORT, 2006; HEIN, 2007). E até mesmo a existência de manuais de pesquisa qualitativa sobre empreendedorismo (NEERGAARD; ULHØI, 2007).

\subsection{PESQUISA PARTICIPANTE E O CONHECIMENTO SOBRE O FENÔMENO EMPREENDEDOR SOCIAL}

A PP desenvolveu-se na América Latina num período em que muitos dos países da região estavam submetidos a ditaduras militares. Os criadores da nova modalidade de pesquisa, por sua vez, eram pessoas com histórico de participação em movimentos sociais populares, como as comunidades eclesiais de base, muitas vezes animadas pela teologia da libertação (BRANDÃO; STECK, 2006). Daí porque durante o regime autoritário no Brasil a PP foi encarada com muita desconfiança pelos governantes.

Bem antes da redemocratização do país, no entanto, a PP passou a ser reconhecida e praticada em ambientes acadêmicos. Assim, no Brasil, desde o final da década de I970, vêm sendo realizadas pesquisas participantes em campos como educação, saúde pública e desenvolvimento comunitário. Pesquisas voltadas para o estudo do empreendedorismo ainda são em pequeno número. Como exemplo, podem-se citar as pesquisas realizadas por Camilotti (200I) com o objetivo de elaborar procedimentos de integração para o desenvolvimento local, a partir do estudo de empreendedorismo, e por Nasciutti et al. (2003) para verificar como os princípios da doutrina do cooperativismo são representados no discurso dos cooperativados e dos técnicos e em suas práticas cotidianas no Rio de Janeiro.

Há relatos de PP realizadas em países africanos sobre empreendedorismo social. Groot e Röling (I998) realizaram um estudo com a finalidade de procurar alternativas para apoiar pequenos proprietários agrícolas em países africanos. 
Sanginga et al. (2004) realizaram pesquisa em Uganda, Tanzânia e Malawi, com o objetivo da capacitar grupos e comunidades rurais em áreas marginais para identificação e avaliação de oportunidades de mercado.

$\mathrm{Na}$ África do Sul vêm sendo desenvolvidos projetos de PP com grupos de empreendedores portadores de deficiência. Stewart e Bhagwanjee (I999) analisaram o processo empreendedor num grupo de autoajuda. Van Niekerk, Lorenzo e Mdlokolo (2006) realizaram pesquisa numa comunidade de empreendedores portadores de deficiência. Esta última pesquisa, por sua vez, prosseguiu com estudo para verificar esferas de negociação de parcerias com empreendedores portadores de deficiência (LORENZO; VAN NIEKERK; MDLOKOLO, 2007).

Em países asiáticos também podem ser encontrados relatos de PP no campo do empreendedorismo. Em Bangladesh, o International Rice Research Institute (IRRI) desenvolve pesquisas participantes com o propósito de proporcionar bemestar aos produtores e consumidores de arroz, particularmente àqueles com baixos rendimentos (HOSSAIN, 2002). Em diversos países do Terceiro Mundo o desenvolvimento da PAP é apoiado por organizações estrangeiras. Assim, há registros de pesquisas desenvolvidas em Bangladesh (RESEARCH INICIATIVES BANGLADESH, 2004), Butão, Burkina-Faso, Burundi, Cambodja, China e Cuba, com a colaboração do International and Development Center, do Canadá (GONSALVES et al., 2005). A Universidade de York, também do Canadá, promove a pesquisaação participante para subsidiar programas voltados à ampliação da capacidade dos nativos para promover o desenvolvimento sustentável nas áreas de pesca, mineração e florestas (URACCAN, s. d.). Também no Brasil trabalhos voltados para a constituição de cooperativas populares já vêm sendo desenvolvidos como forma de extensão universitária (GUIMARÃES, 2002).

Embora a PP esteja identificada com o Terceiro Mundo, também é praticada em países desenvolvidos. Isso porque, a despeito da riqueza, nesses países também são encontradas diversidades regionais e sociais. Na Suécia, por exemplo, desenvolveu-se um projeto de pesquisa numa "região vulnerável". A justificativa foi a de que, de acordo com o pensamento de Paulo Freire, as iniciativas empreendedoras são restringidas pelo discurso oficial que suprime a habilidade de grupos particulares da sociedade de se verem como empreendedores (BERGLUND; JOHANSSON, 2007).

\section{CONSIDERAÇÕES FINAIS}

A pesquisa participante tem sido e poderá continuar sendo alvo de críticas, já que seus criadores declaram explicitamente que ela não tem como propósi- 
to a construção de um conhecimento neutro e objetivo. O envolvimento do(a) pesquisador(a) com a realidade observada constitui sério obstáculo para que essa modalidade de pesquisa seja reconhecida como científica, pelo menos da perspectiva do positivismo, ainda dominante no campo da administração. Mais ainda quando esse envolvimento se dá com grupos de pessoas que se encontram na condição de excluídos não apenas da economia formal, mas da própria sociedade. Mas as experiências concretas, verificadas ao longo de praticamente três décadas, remetem a indagações acerca da eficácia da pesquisa participante no fornecimento de respostas para problemas sociais.

Esse quadro tende, no entanto, a se modificar, sobretudo num momento em que a administração se apresenta cada vez mais como administração de organizações em um mundo complexo, e não apenas como administração de empresas. Estudar como os grupos se organizam e de entre muitos olhares ter a visão sem neutralidade de membro de um grupo é vital para a compreensão de fenômenos empreendedores.

Embora tenha sido constituída em boa parte à margem da universidade, a PAP vem ganhando o apoio de pesquisadores não apenas da América Latina, mas de praticamente todos os continentes. Muitas pesquisas vêm sendo desenvolvidas de forma multicêntrica, graças ao apoio de universidades, organismos públicos e organizações não-governamentais, sobretudo de países europeus. A PAP está, pois, alcançando sua maioridade acadêmica e já se dispõe de elementos suficientes para verificar o quanto pode ser adequada para a investigação no campo do empreendedorismo social e para a efetivação das medidas a que se propõe.

Em relação ao empreendedorismo social, especificamente, sugere-se que a avaliação da PAP se dê especialmente sob a óptica da aplicação edificante proposta por Santos (1989). Há que avaliar primeiramente o quanto a pesquisa participante é eficaz no sentido de ampliar a capacidade de cada participante para agir e se responsabilizar pelo seu próprio aprendizado e experiência.

Independentemente da avaliação externa da pesquisa, o empreendedorismo social em si pode ser mais bem compreendido por intermédio de sua própria construção conjunta por um grupo de pessoas. Ladkin (2005) nos lembra que um martelo só pode realmente ser conhecido quando usado para martelar. Um terceiro aspecto que deve ser considerado quando da utilização da PAP é a possibilidade de essa fazer parte da articulação produtiva dos recursos existentes em determinados grupos sociais. É pouco provável que a solução para o desemprego e pobreza de vastas camadas da população venha das empresas formais, quando essas empresas investem cada vez mais em tecnologias avançadas e excludentes de mão-de-obra. Tampouco o setor público pode absorver essa massa. 
A PAP em suas diferentes formas, independentemente da ideologia a que esteja alinhada, pode integrar esse leque de esforços, pelas características de aprendizado conjunto, interdisciplinaridade e interação multicultural antes mencionadas. Seja para o apoio à gestão de pequenas e médias empresas, seja para a incubação de empresas de alta tecnologia ou a serviço de propósitos emancipatórios e de autonomia popular, é mais um instrumento na criação da rede de sustentação para iniciativas locais. Como afirma Freire (2005, p. 97): "Para o educador-educando dialógico e problematizador, o conteúdo programático não é uma doação ou uma imposição", mas sim uma forma de devolução organizada e sistematizada às comunidades com que se trabalha daqueles elementos que estas lhe entregaram de forma desestruturada.

Considerando as características do empreendedorismo social, a PAP apresenta-se como opção adequada à investigação nesse campo. As pessoas que integram os segmentos populares manifestam crenças e valores que de alguma forma se distinguem não apenas das crenças e valores das classes dominantes, mas muitas vezes das crenças e valores dos próprios pesquisadores. Muitos dos empreendedores oriundos desses segmentos tendem a ver com certa desconfiança os procedimentos científicos adotados pela comunidade acadêmica. E como a PAP é construída graças ao contato com integrantes de comunidades populares, contribui para que os pesquisadores melhor compreendam o mundo dos outros, assimilem sua lógica e até mesmo sintam como eles sentem. A pesquisa-ação participante constitui, pois, um instrumento formativo tanto para os pesquisadores quanto para os sujeitos da pesquisa. Ao longo de seu processo, ela incorpora práticas educativas que transcendem seus objetivos iniciais. O pesquisador qualifica-se ao entrar em contato com a cultura local, incorporar seus elementos, superar-se em seus questionamentos e surpreender-se com as respostas do grupo. Os sujeitos da prática, por sua vez, além de obter respostas para os problemas de seu cotidiano, envolvem-se em processos coletivos ligados a suas experiências e valores; surpreendem-se ao se confrontarem com seus pressupostos de vida e formação e criam coragem para empreender mudanças.

A consolidação da PAP no campo do empreendedorismo requer por parte do pesquisador a adoção de algumas posturas que são adotadas na pesquisa educacional. A entrada do pesquisador em grupos socialmente menos favorecidos requer um trabalho prévio de construção de um universo comum de significados culturais, que se aproxima bastante e correspondem ao universo vocabular mínimo, conforme conceito proposto por Freire (2005) nos processos de alfabetização de adultos. A construção desse universo comum é feita mediante o diálogo sobre o objeto a ser conhecido e sobre a representação da realidade a ser transformada, e é realizada por meio de questões provocadas pelo pesquisador principal, mediante o aprofun- 
damento das leituras de mundo dos sujeitos envolvidos. O debate que surge daí possibilita uma releitura da realidade de onde pode resultar um maior engajamento dos participantes em práticas políticas com vista à transformação da realidade e do surgimento de organizações antes não existentes ou melhorias de outras.

Os pesquisadores participativos não reivindicam um conhecimento livre de contexto, e sim a validade do conhecimento científico intermediado pelo teste da mudança e transformação social em que se está engajado. Trata-se de levar o conhecimento acadêmico para fora da universidade, em especial da Faculdade de Administração, e quebrar seu ciclo autoreferente. Se isso é importante em países desenvolvidos, mais ainda o é em países com amplos bolsões de miséria e carência de informações básicas sobre a condução de pequenos e médios negócios, cooperativistas ou não, de base tecnológica ou não.

Os pesquisadores participativos se afastam da idéia de objetividade. Rorty (I998) nos lembra que as intenções expressas em termos como objetividade, racionalidade, verdade etc. podem ser alcançadas de outra forma pela idéia de "comunidade", no sentido de espaço de produção de acordos intersubjetivos e de (re)invenção do modo de ser das pessoas e dos seus vocabulários. Se objetividade for reconcebida como intersubjetividade, não fará mais sentido buscar por uma realidade não-humana presente na natureza ou nas organizações sociais. A pesquisa-ação participante pode produzir redescrições solidárias mais do que pesquisas objetivas, pois carrega a noção de pertencimento ao grupo.

Há certamente limitações, uma vez que quando se fundem processos educativos e organizacionais poder-se-ia crer que apenas aprender bastaria para atender às necessidades de determinadas comunidades. É necessário, portanto, estar alerta para os riscos éticos em que incorrem pesquisadores bem intencionados, mas sem os recursos e tempo necessários, de abandonar grupos e projetos em momentos inadequados, antes que a sustentabilidade desses projetos tenha sido alcançada. Nesses casos, trabalhos com grupos populares carentes de transformações reais e sustentáveis podem acabar em frios relatórios voltados apenas para o espaço fechado e o ritmo previsível de rituais acadêmicos inócuos e autoreferentes.

Interessa, portanto, que as pesquisas participativas realizadas com membros de comunidades e grupos que se encontram de alguma forma excluídos conduzam a algum tipo de ação que contribua para sua emancipação, no sentido de “justiça capacitante” (SANTOS, 2007, p. 270). Isso significa a adoção de princípios que permitam a capacitação destes grupos não apenas por meio do estímulo à igualdade, mas também por meio do respeito das diferenças. A PAP pode ser vista como uma promessa no campo do estudo do empreendedorismo, capaz de envolver múltiplas comunidades, como as constituídas por grupos de baixíssima renda, minorias étnicas e culturais e portadores de necessidades especiais de 
apoiar cooperativas e organizações sem fins lucrativos. Sua efetivação, no entanto, não constitui tarefa simples, pois está condicionada a múltiplos fatores. Entre eles, a existência de pesquisadoras e pesquisadores dispostos a assumir os longos prazos e os muitos riscos inerentes a esse tipo de intervenção e, sobretudo, que essas pesquisadoras e pesquisadores percebam um clima político favorável à realização deste tipo de investigação por parte da academia. Isso para que a área de ensino e pesquisa em administração possa contribuir em relação a grupos carentes e excluídos de maneira que "[...] as aprendizagens de nossas práticas nos ajudem a criar novas práticas transformadoras, porque a educação da América Latina requer urgentemente uma transformação de fundo e radical", 2006 , p. 242.

Os autores deste trabalho acreditam que essa promessa da pesquisa-ação participante como estratégia de pesquisa e transformação da realidade se dará com a junção de robustez epistemológica e flexibilidade metodológica. É importante desenvolver plataformas de cooperação com outras formas de pesquisa qualitativa que não usem o conceito da PA, mas que de qualquer forma estejam comprometidas com a transformação da sociedade. Acima de tudo, é hora de deixar de lado velhas disputas e formar novas coalizões para enfrentar os desafios sociais e ambientais de nossos tempos.

\section{REFERÊNCIAS}

ALBAGLI, S.; MACIEL, M. L. Capital social e desenvolvimento local. In: LASTRES, H. M. M.; CASSIOLATO, J. E.; MACIEL, M. M. (Org.). Pequena empresa: cooperação e desenvolvimento local. Rio de Janeiro: Relume Dumará, 2003. p. 423-440.

ALVORD, S. A.; BROWN, L. D.; LETTS, C. W. Social entrepreneurship and societal transformation: an exploratory study. The Journal of Applied Behavioral Science, v. 40, n. 3, p. 260-282, 2004. BARAZANGI, N. M. An ethical theory of action research pedagogy. Action Research, v. 4, n. I, p. 97-II6, 2006.

BERGLUND, K.; JOHANSSON, A. W. Entrepreneurship, discourses and conscientization in processes of regional development. Entrepreneurship \& Regional Development, v. I9, n. 6, p. 499-525, 2007.

BERTALANFFY, L. Teoria geral dos sistemas. Petrópolis: Vozes, I973.

BOXILL, I. Unearthing black entrepreneurship in the Caribbean: exploring the culture and MSE sectors, v. 22, n. II, p. 32-45, 2003.

BRANDÃO, C. R. Pesquisa participante. São Paulo: Brasiliense, I98I.

BRANDÃO, C. R.; STECK, D. Participar-pesquisar. In: BRANDÃO, C. R. (Org.). Repensando a pesquisa participante. São Paulo: Brasiliense, I999. p. 7-I4.

Pesquisa participante: a partilha do saber. In: (Org.). Pesquisa participante: o saber da partilha. São Paulo, Aparecida: Idéias e Letras, 2006. 295 p. 
- A PESQUISA-AÇÃO PARTICIPANTE COMO ESTRATÉGIA METODOLÓGICA PARA O ESTUDO... • MARCOS BIDART CARNEIRO DE NOVAES • ANTONIO CARLOS GIL

BRIDGES, W. Um mundo sem empregos: os desafios da sociedade pós-industrial. São Paulo: Makron, I995.

BRUNI, A. et al. Gender and entrepreneurship: an ethnographical approach. London: Routledge, 2005. BURREL, G.; MORGAN. G. Sociological paradigms and organizational analysis. London: Heinemann Educational Books, I979.

CAMILOTTI, L. Procedimentos de integração para o desenvolvimento local a partir dos princípios do empreendedorismo. Florianópolis, 200I. Dissertação (Mestrado em Engenharia da Produção)-Universidade Federal de Santa Catarina.

COOPER, D. R.; SCHINDLER, P. S. Métodos de pesquisa em administração. Porto Alegre: Bookman, 2003.

COPE, J. Researching entrepreneurship through phenomenological inquiry. International Small Business Journal, v. 23, n. 2, p. 163-189, 2005.

DEHLER, G. E.; EDMONDS, R. K. Using action research to connect practice to learning: a course project for working management students. Journal of Management Education, v. 30, n. 5, p. 636669 , oct. 2006.

DEMIRDJIAN, Z. S. Social entrepreneurship: sustainable solutions to societal problems. Journal of American Academy of Busines, Cambridge, v. II, n. I, p. I-2, mar. 2007.

DEMO, P. Pesquisa participante: mito e realidade. Rio de Janeiro: Senac, I984.

ELDEN, M. Three generations of worker democracy research in Norway. In: COOPER, C. L.; MUMFORD, E. (Ed.). The quality of work life in Europe. London: Associate Business Press, I979.

FALS BORDA, O. Reflexiones sobre la aplicación del método de estudio-acción en Colombia. In: SIMPOSIO SOBRE POLÍTICA DE ENSEÑANZA E INVESTIGACIÓN EN CIENCIAS SOCIALES. doc. n. 8. p. I9-24. Pontifica Universidad Católica del Perú. Lima, I972.

Por la praxis: cómo intervenir en la realidad para transformarla. In: CRÍTICA Y POLÍTICA EN CIENCIAS SOCIALES. Simposio Mundial de Cartagena. Bogotá: Punta de Lanza, I977. La ciencia y el pueblo. Bogotá: Punta de Lanza, i980.

Aspectos teóricos da pesquisa participante. In: BRANDÃO, C. R. (Org.). Pesquisa participante. São Paulo: Brasiliense, I982.

Participatory (action) research in social theory: origins and challenges. In: REASON, P.; BRADBURY, H. Handbook of action research: participative inquiry and practice. London: Sage Publications, 200I. p. 27-37.

FERNÁNDEZ-KELLY, P.; KONCZAL, L. "Murdering the alphabet”: identity and entrepreneurship among second-generation Cubans, West Indians, and Central Americans. Ethnic and Racial Studies, v. 28, n. 6, p. II53-II8I, nov. 2005.

FRANCO,M.A.S.Pedagogia da pesquisa-ação. Educaçãoe Pesquisa.v.3I,n.3,p.483-502, set.-dez. 2005 . FREIRE, P. Cartas à Guiné Bissau: registros de uma experiência em progresso. Rio de Janeiro: Paz e Terra, I977.

Ação cultural para a liberdade. Rio de Janeiro: Paz e Terra, I98I.

Pedagogia do oprimido. Rio de Janeiro: Paz e Terra, 2005.

GAJARDO, M. Educação popular e conscientização no meio rural latino-americano. In: WERTHEIN, J.; BORDENAVE, J. D. Educação rural no Terceiro Mundo. Rio de Janeiro: Paz e Terra, I98I.

Pesquisa participante: propostas e projetos. In: BRANDÃO, C. R. (Org.). Repensando a pesquisa participante. 3 ed. São Paulo: Brasiliense, I999. p. I5-50. 
GIANOTTEN, V.; WITT. Pesquisa participante em um contexto de economia camponesa. In: BRANDÃO, C. R. (Org.). Repensando a pesquisa participante. 3 ed. São Paulo: Brasiliense, I999. p. I58-188.

GIL, A. C. O método fenomenológico na pesquisa da administração. Caderno de Pesquisa de PósGraduação IMES, ano 4, n. 8, I sem. 2003.

GODOY, A. Estudo de caso qualitativo. In: GODOI, C. K.; BANDEIRA-DE-MELLO, R. ; SILVA, A. B. Pesquisa qualitativa em organizações. São Paulo: Saraiva, 2006.

GONSALVES, J. et al. (Ed.). Participatory research and development for sustainable agriculture and natural resource management: a sourcebook. Otawa: International Potato Center-Users' Perspectives With Agricultural Research and Development, Laguna, Philippines and International Development Research Centre, 2005.

GREVE, A.; SALAFF, J. W. Social networks and entrepreneurship. Entrepreneurship theory and practice, Baylor University, Fall 2003.

GROOT, A.; RÖLING, N. Participatory action-research for improving knowledge systems' performances in Africa. In: DOLBERG, F. H.; PETERSEN, P. (Ed.). Alternatives to the training and visit system: proceedings of a workshop. Mansholt: Mansholt Social Sciences, I998.

GUIMARÃES, C. Ossos do ofício: cooperativas populares em cena aberta. Rio de Janeiro: ITCP/ Coppe/UFRJ, 2002.

HEIN, E. What skills do emerging entrepreneurs need to learn? In: Global Entrepreneurship Research Conference. Proceedings of the 3rd Annual San Francisco - Silicon Valley 2007 Global Entrepreneurship Research, 2007.

HOSSAIN, M. Promoting rural non-farm economy of Bangladesh. CPD-IRRI POLICY BRIEF Dhaka: Centre for Policy Dialogue. 2002. Disponível em:

<http://www.cpd-bangladesh.org/publications/cpdiri/cpdiri_3.pdf.>. Acesso em: 3I dez. 2007.

JAMES, A.; MILENKIEWICZ, M. T.; BUCKNAN, A. Participatory action research for educational leadership: using data-driven decision em contrapartida e da forma dialética, das bases para os intelectuais engajados, making to improve schools. New York; London; New Delhi: Sage, 2007.

IARA HOLLIDAY, O. Sistematização das experiências: algumas apreciações. In: BRANDÃO, C. R.; STRECK, D. (Orgs.). Pesquisa participante: o sabor da partilha. São Paulo, Aparecida: Idéias e Letras, 2006. p. 7-20.

JENKINS, T. Revitalizing rural america: one community at a time. Rural TelecommuniCtions, v. 24, n. 6, p. 28-33, nov./dez. 2005 .

JOHANNSEN, A. Participatory-action-research in post conflict situations: the exemples of WarTorn Societies Project. In: Berghof handbook for conflict transformation. Berlin: Berghof Research Center for Constructive Conflict Management, 200I.

KINDON, S.; PAIN., R.; KESBY, M. Participatory action research approaches and methods connecting people: participation and place. London: Routledge, 2007.

KOCH, T.; KRALIK, D. Participatory action research in health care. Victoria: Blackwell, 2006.

LADKIN, D. The enigma of subjectivity. Action Research, v. 3, n. I, p. I08-I26, 2005.

LE BOTERF, G. Pesquisa participante: propostas e reflexões metodológicas. In: BRANDÃO, C. R. (Org.). Repensando a pesquisa participante. São Paulo: Brasiliense, I984.

LEWIN, K. Action-research and minority problems. Journal of Social Issues, n. 2, p. 34-36, I946.

LINDSAY, N. J. Toward a cultural model of indigenous entrepreneurial attitude. Academy of Marketing Science Review, v. 5, 2005. Disponível em:

$<$ http://www.amsreview.org/articles/lindsay05-2005.pdf>. Acesso em: 29 jun. 2007. 
- A PESQUISA-AÇÃO PARTICIPANTE COMO ESTRATÉGIA METODOLÓGICA PARA O ESTUDO... • MARCOS BIDART CARNEIRO DE NOVAES • ANTONIO CARLOS GIL

LORENZO, T.; VAN NIEKERK, L.; MDLOKOLO, P. Economic empowerment and black disabled entrepreneurs: negotiating partnerships in Cape Town, South Africa. Disabil Rehabil, v. 29, n. 5, p. 429-436, 2007 .

MACKE, J. A pesquisa-ação como estratégia de pesquisa participativa. In: GODOI, C. K. et al. Pesquisa qualitativa em organizações. São Paulo: Saraiva, 2006.

MARTINS, G. Estudo de caso: uma estratégia de pesquisa. São Paulo: Atlas, 2006.

MALINOWSKI, B. K. Argonautas do Pacífico Ocidental: um relato do empreendimento e da aventura dos nativos nos arquipélagos da Nova Guiné Melanésia. São Paulo: Abril Cultural, i978.

MARTINEZ, I. B.; PIRES, M. L. L. S. Cooperativas e revitalização dos espaços rurais: uma perspectiva empresarial e associativa. Cadernos de Ciência e Tecnologia, Brasília, v. I9, n. I, p. 99-II8, 2002.

McTAGGART, R. Participatory action-research. Suny Press: Albany, I997.

McINTYRE. Participatory action research. New York; London; New Delhi: Sage, 2007.

McMURRAY, A. J.; PACE, R. W. Action-research in learning organizations. New York; London; New Delhi: Sage, 2004 .

McNIFF, J. Action-research in organizations. London: New Fetter Lane, 2000.

MELO NETO, F. P.; FROES, C. Empreendedorismo social: a transição para a sociedade sustentável. Rio de Janeiro: Qualitymark, 2004.

MEYER, J. Bringing practicality and theory together: current practical examples to support the theory of teaching project management. The Business Review, Cambridge, v. 5, n. 2, p. 276-279, 2006.

MILLS, A. Sociological paradigms and organizational analysis: an interview with Gareth Morgan. Aurora, v. 12, n. 2, p. 42-46, 1987.

MONTEIRO, S. Pesquisa-ação e produção de conhecimento na formação docente. In: ENDIPE - ENCONTRO NACIONAL DE DIDÁTICA E PRÁTICA DE ENSINO, I6. Porto Alegre, 2007.

MORIN, E. Introdução ao pensamento complexo. Porto Alegre: Sulina, 2006.

NASCIUTTI, J. C. R. et al. Cooperação e autonomia: desafios das cooperativas populares. Cadernos de Psicologia Social do Trabalho, USP, São Paulo, v. 6, n. I, p. 89-104, 2003.

NEERGAARD, H.; ULHØI, J. (Ed.). Handbook of qualitative research methods in entrepreneurship. Cheltenham: Edward Elgar, 2007.

OLSON, J. M. Are artesanal cooperatives in Guatemala unraveling? Human Organization, v. 58, n. I, p. 54-66, I999.

PARSON, T. The social system. New York: Free Press, I95I.

PAULA, A. P. P. Teoria crítica nas organizações. São Paulo: Thomson Learning, 2008.

PEREIRA, F. I. Uma investigação empírica do conhecimento como meio de promoção do empreendedorismo social nas comunidades indígenas amazônicas. In: SIMPÓSIO INTERNACIONAL DE GESTÃO DO CONHECIMENTO. Anais do Congresso, Curitiba, 2003.

PINTO, J. B. Educación liberadora: dimensión teórica y metodológica. Buenos Aires: Búsqueda, I976.

REASON. P.; BRADBURY, H. Handbook of action research: participative inquiry and practice. London; Thousand Oaks; New Delhi: Sage, 2008.

RESEARCH INICIATIVES BANGLADESH. International Workshop on Participatory Action Research. Proceedings of the International Workshop Dhaka, 2004. Disponível em:

$<$ http://www.rib-bangladesh.org/int_workshop.php>. Acesso I5 jan. 2008.

RORTY, R. Objectivity, relativism, and truth. Philosophical Papers v. 1. New York: Cambridge University Press, 1998. 
SANGINGA, P. C. et al. Enabling rural innovation in Africa: an approach for integrating farmer participatory research and market orientation for building the assets of ruralpoor. Uganda Journal of Agricultural Sciences, v. 9, p. 942-957, 2004.

SANTOS, B. de S. Introdução a uma ciência pós-moderna. Rio de Janeiro: Graal, I989.

(Org.). Democratizar a democracia: os caminhos da democracia participativa. Rio de Janeiro: Civilização Brasileira, 2002.

A crítica da razão indolente: contra o desperdício da experiência. São Paulo: Cortez, 2007.

SEYMOUR, R. G. Hermeneutic phenomenology and international entrepreneurship research. Journal of International Entrepreneurship, v. 4, n. 4, dez. 2006.

SHAW, E.; CARTER, S. Social entrepreneurship: theoretical antecedents and empirical analysis of entrepreneurial processes and outcomes. Journal of Small Business and Enterprise Development, v. I4, n. 3, p. 418-434, 2007.

SILVA E SILVA, M. O. Refletindo a pesquisa participante. São Paulo: Cortez, I99I.

Reconstruindo um processo participativo na produção do conhecimento: uma concepção e uma prática. In: BRANDÃO, C. R.; STRECK, D. (Org.). Pesquisa participante: a partilha do saber. São Paulo, Aparecida: Idéias e Letras, 2006. p. I23-I5I.

STEWART, R.; BHAGWANJEE, A. Promoting group empowerment and self-reliance through participatory research: a case study of people with physical disability. Disabil Rehabil, v. 2I, n. 7, p. 338-345, jul. I999.

THIOLLENT, M. Metodologia da pesquisa-ação. São Paulo: Cortez, I985. Pesquisa-ação nas organizações. São Paulo: Atlas, I997.

THOMAS, A. The rise of social cooperatives in Italy. International Journal of Voluntary and Nonprofit Organizations, v. I5, n. 3, p. 243-263, set. 2004.

THORSRUD, E. Democracy at work: norwegian experiences with non-bureaucratic forms of organization. Applied Behavioral Science, v. I3, n. 3, p. 4I0-421, I977.

TRIPP, D. Pesquisa-ação: uma introdução metodológica. Educação e Pesquisa, São Paulo, v. 3I, n. 3, p. 443-466, set./dez. 2005 .

UFRJ (SOLTEC/NUPEM). Pesquisa-ação na cadeia produtiva da pesca em Macaé. Relatório de Pesquisa 2. 2005 .

URACCAN (UNIVERSITY OF THE AUTONOMOUS REGIONS OF THE CARIBBEAN COAST OF NICARAGUA). URACCAN Linkage Project at CERLA. York University: Human Resources for Sustainable Development in Nicaragua's. Disponível em: <http://www.yorku.ca/cerlac/URACCAN/plans.html>. Acesso em: 7 jan. 2008.

VALADARES, L. Os dez mandamentos da observação participante. Revista Brasileira de Ciências Sociais, v. 22, n. 63, p. I53-I55, 2007.

VAN NIEKERK, L.; LORENZO, T.; MDLOKOLO, P. Understanding partnerships in developing disabled entrepreneurs through participatory action research. Disabil Rehabil, v. 28, p. 323-33I, 2006. WEERAWARDENA, J.; MORT, G. S. Investigating social entrepreneurship: a multidimensional model. Australia Journal of World Business, v. 4I, n. I, p. 2I-35, fev. 2006.

WHYTE, W. F. Participatory action research. New York; London; New Delhi: Sage, I99I. Sociedade de esquina. Rio de Janeiro: Jorge Zahar, 2005.

YIN, R. K. Estudo de caso: planejamento e método. Porto Alegre: Bookman, 200 I.

ZIKMUND, W. G. Business research methods. Cincinnati: South-Western College Publishing, 2003. 